\title{
molecules
}

ISSN 1420-3049

(C) 2007 by MDPI

www.mdpi.org/molecules

Review

\section{Supra-molecular Association and Polymorphic Behaviour In Systems Containing Bile Acid Salts.}

\author{
Marco Calabresi, Patrizia Andreozzi, and Camillo La Mesa*
}

Dipartimento di Chimica and SOFT-INFM-CNR Research Centre, Università "La Sapienza”, P.le A. Moro 5, Roma, I-00185, Italy

* Author to whom correspondence should be addressed; E-mail: camillo.lamesa@uniroma1.it;

Tel. +39-06-491694 (direct); +39-06-49913707; Fax. +39-06-490631

Received: 9 May 2007; in revised form: 12 July 2007 / Accepted: 12 July 2007 / Published: 7 August 2007

\begin{abstract}
A wide number of supra-molecular association modes are observed in mixtures containing water and bile salts, BS, (with, eventually, other components). Molecular or micellar solutions transform into hydrated solids, fibres, lyotropic liquid crystals and/or gels by raising the concentration, the temperature, adding electrolytes, surfactants, lipids and proteins. Amorphous or ordered phases may be formed accordingly. The forces responsible for this very rich polymorphism presumably arise from the unusual combination of electrostatic, hydrophobic and hydrogen-bond contributions to the system stability, with subsequent control of the supra-molecular organisation modes. The stabilising effect due to hydrogen bonds does not occur in almost all surfactants or lipids and is peculiar to bile acids and salts. Some supra-molecular organisation modes, supposed to be related to malfunctions and dis-metabolic diseases in vivo, are briefly reported and discussed.
\end{abstract}

Keywords: Bile Salts, Solutions, Micelles, Liquid Crystals, Gels, Fibres, Solids. 


\section{Introduction}

The solution behaviour of bile salts, BS, by-products of the steroidal pool in vivo, is of outstanding relevance in many relevant aspects of the entero-hepatic circulation in mammals [1]. Previous studies on these substances focused on BS-related dis-metabolic diseases in the intestine, the liver, the gall bladder and the biliary ducts [2-4]. In particular, the lithic activity of $B S$ towards gallstones was extensively investigated [5-9]. Use of bile acids, BA, (the cholic, deoxycholic, chenodeoxycholic, dehydrocholic or ursodeoxycholic acids and their derivatives, [10]) in gallstone removal was replaced by surgical methods and pharmaceutical formulations based on BS became obsolete.

Consistent amounts of BS operate in the entero-hepatic circulation and the bile of humans is a reservoir for processes occurring in other metabolic pathways. BS are irritant towards specific tissues when their concentration exceeds proper limits [11,12]. Their distribution in the body obeys not fully understood rules.

BS control biochemical processes related to insulin production, as well as other metabolic pathways $[13,14]$. In such cases, $B S$ amount in such organs (in the $\mu$ mole $\mathrm{L}^{-1}$ range) is well below their association threshold and they are bound to proteins or enzymes [15-17]. In other words, the questions to be answered move from colloid chemistry towards biochemical and molecular aspects. Although extremely interesting from a fundamental viewpoint, the biochemical aspects do not involve supramolecular association and are outside the purposes of this presentation.

Bile salts are effective fat solubilising agents and Harvey, who discovered blood circulation in humans, first demonstrated the solvent capacity of ox bile [18]. Compared to other biological surfactants, their solvent activity towards cholesterol, with which they share the steroidal pool, is moderate, unless saponins [19,20], lipids [21] or glycerides [22], are present. Their solvent capacity toward sterols and metabolic fats depends on the structure of the aggregates they form. Solid BS also form inclusion compounds with alkanols, fatty acids, polyenes, retinoids and other species [23,24]. Bile salts interact with a wide variety of compounds in solution and in real matrices (see Scheme 1). Obviously, BS may interact with more species.

Scheme 1. The most common chemical substances interacting with bile salts in aqueous solution or in vivo and significantly affecting their supra-molecular association modes.

\section{Acids}

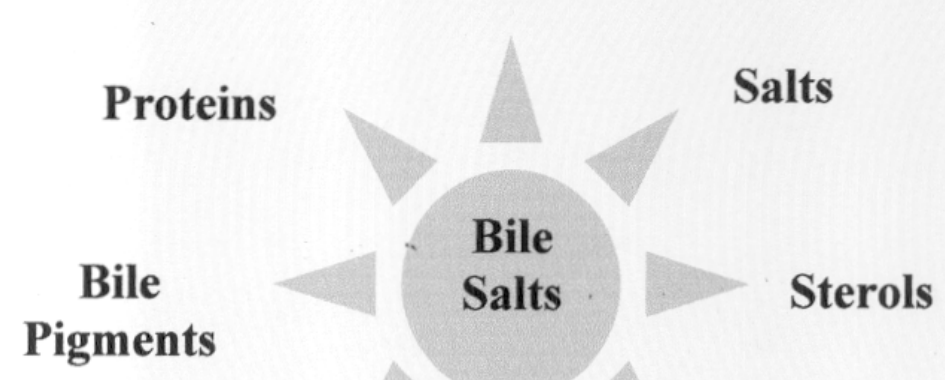

Glycerides

Lipids 
The above peculiarities have attracted significant interest from the scientific community. They are ascribed to the unconventional structure of $B S$, compared to naturally occurring surfactants and lipids. $B S$ are formed by four aliphatic rings fused together by covalent bonds, with one to three $\mathrm{OH}$ groups facing outwards from the main steroidal skeleton [25]. Together with the polar head groups, the $\mathrm{OH}$ ones impart a side-to-side polarity to BS. That's why BS are substantially different from surfactants and lipids. The latter show regional polarity, with alkyl groups pending from the polar ones [26], whereas BS possess “surface” polarity, as indicated in Figure 1.

Figure 1. Comparison of the chemical structures of fatty acids salts, left, di-glycerides, in the centre, and BS, respectively. Oxygen atoms are in black, the glycerol carbons of diglycerides in dark grey. Molecular sizes are not in scale.

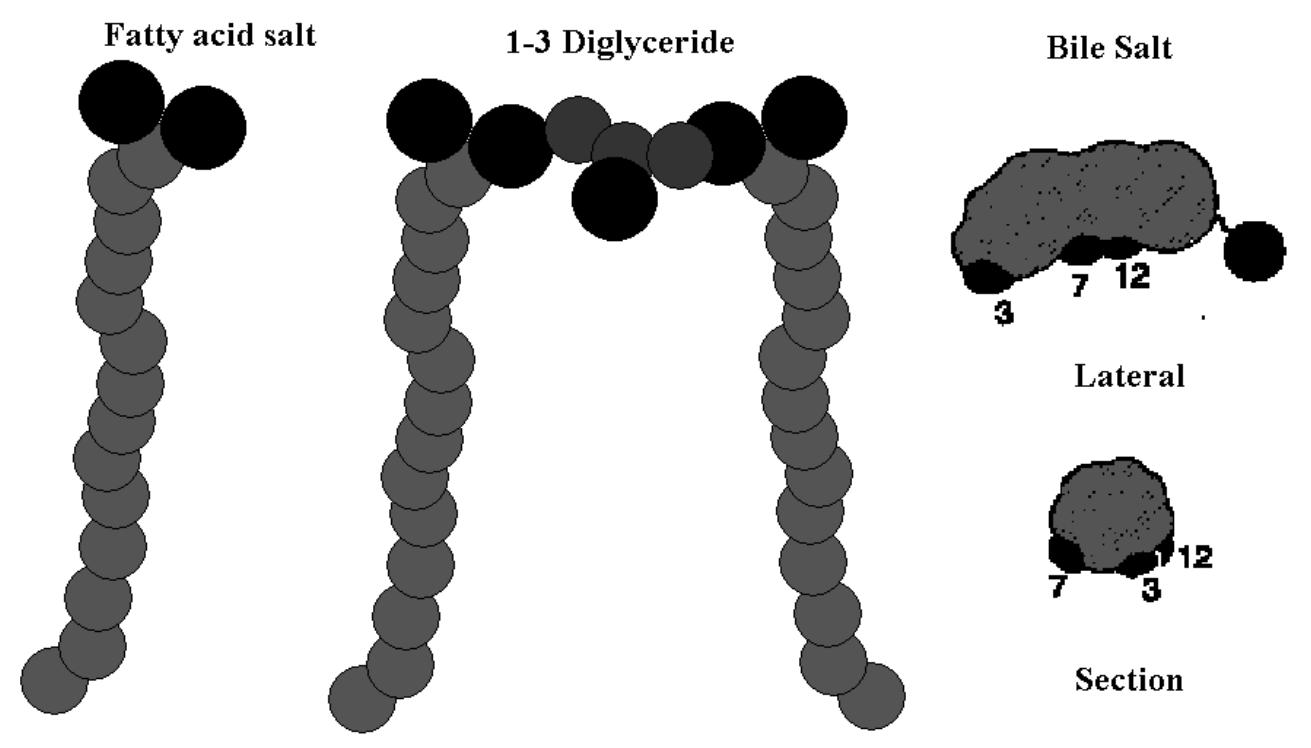

It is interesting to define the nature of forces responsible for the formation of the mixed aggregates they form with surfactants and lipids [27]. In this contribution, some aspects related with the supramolecular association modes of $B S$ in water are dealt with. Knowledge of these aspects allows aan understanding of why the physical-chemical properties and the subsequent association modes of $B S$ are so exclusive, compared to surfactants and lipids [28]. This contribution focuses on the links between supra-molecular association and eventual dis-metabolic diseases. For these reasons the chemical structure of $B S$ and its links with the possible association modes into aggregates are reported and discussed.

After a brief description of chemical structure, we show that the properties of such substances are concomitant to peculiar association modes, with formation of micelles, solids, and fibres. Binary systems shall be considered first. Studies on the organisation modes of the above substances in presence of surfactants, lipids and proteins are reported too. Ternary and quaternary systems shall be briefly discussed.

A few examples of the links with functional activity in real biological matrices are made in the sections that follow. 


\section{Results and Discussion}

\section{Chemical Structure of Bile Acid Salts}

Conjugation of three $C-6$ aliphatic carbon rings with a five-member one gives the well known steroidal skeleton depicted in Figure 2.

Figure 2. Molecular structure of cholanic acids. $\mathrm{OH}$ groups are indicated by dotted lines, methyl ones by full lines. The arrow indicates a counter-clockwise numbering of carbon atoms.

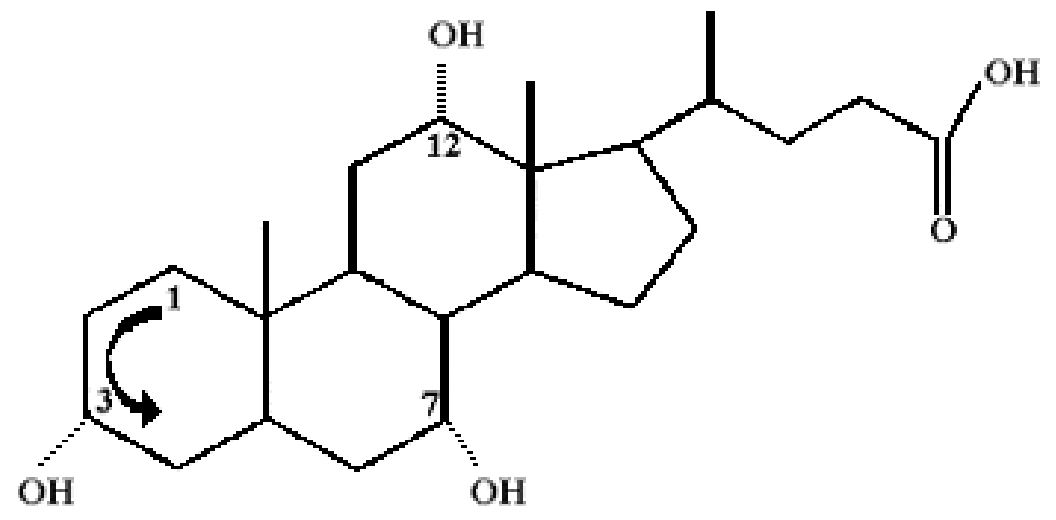

The position of $C$ atoms therein is numbered counter-clockwise and counted relative to that indicated by an arrow. One to three $\mathrm{OH}$ groups are located at different positions of the steroidal skeleton, the most common being $3 \alpha, 7 \alpha$ and $12 \alpha$ [29]. Mono- (litocholic), di- (deoxy, or chenodeoxy, depending on whether the second $\mathrm{OH}$ is in position 7 or 12) and three- (cholic) derivatives occur. In addition, a small polar functionality ( $\mathrm{COOH}$ or its salts) is located at the end of the short polymethylene chain facing outward the $C-5$ ring. The strength of un-conjugated bile acids is known with good accuracy and the same holds for the respective $p K_{a}$ values [30]. Usually, the $\mathrm{COOH}$ functionality of $B A$ is conjugated with glycine and taurine through a peptide bond, giving the corresponding glycoand tauro- derivatives. The latter exist as alkali metal salts and their solution properties are practically insensitive to $\mathrm{pH}$; un-conjugated bile salts, conversely, suffer such drawback.

Many authors investigated basic physical-chemical properties of bile acids and salts, such as solubility and crystal structure [31,32]. The crystal structure of the respective solids depends on the number of $\mathrm{OH}$ groups in the steroidal skeleton. Salts are much more water-soluble than the corresponding acids and are characterised by a lower solubility threshold, the Krafft point [33], at which the molecular species coexists with solid and micelles. Such triple point occurs at much lower temperatures compared to ionic surfactants. It is sensitive to the counter-ion and medium ionic strength [34,35].

\section{Supra-molecular association}

Surfactant solubility in water is limited by the unfavourable interactions of their apolar parts with the solvent. These are the reasons why they self associate into aggregates termed micelles [36]. The process finds analogy with a micro-phase separation (with particle size in the colloidal range). The 
threshold above which association occurs is termed critical micelle concentration, $c m c$. The $c m c$ finds analogy with a solubility limit for the molecular species. The more convincing definition of micellar association is that "the $c m c$ is the value at which surface activity ends and micelle begin to form" [37].

Close to that threshold significant changes in many physical-chemical properties of the solutions occur. The $\mathrm{cmc}$ can be determined by surface tension, conductivity, colligative properties, volumetric methods, light scattering, etc. Such behaviour is shown in Figure 3.

Figure 3. Dependence of some physical-chemical properties on surfactant concentration. The arrow indicates the $\mathrm{cmc}$ value, above which micelles dominate. Concentration scales are normal or logarithmic (in surface tension plots).

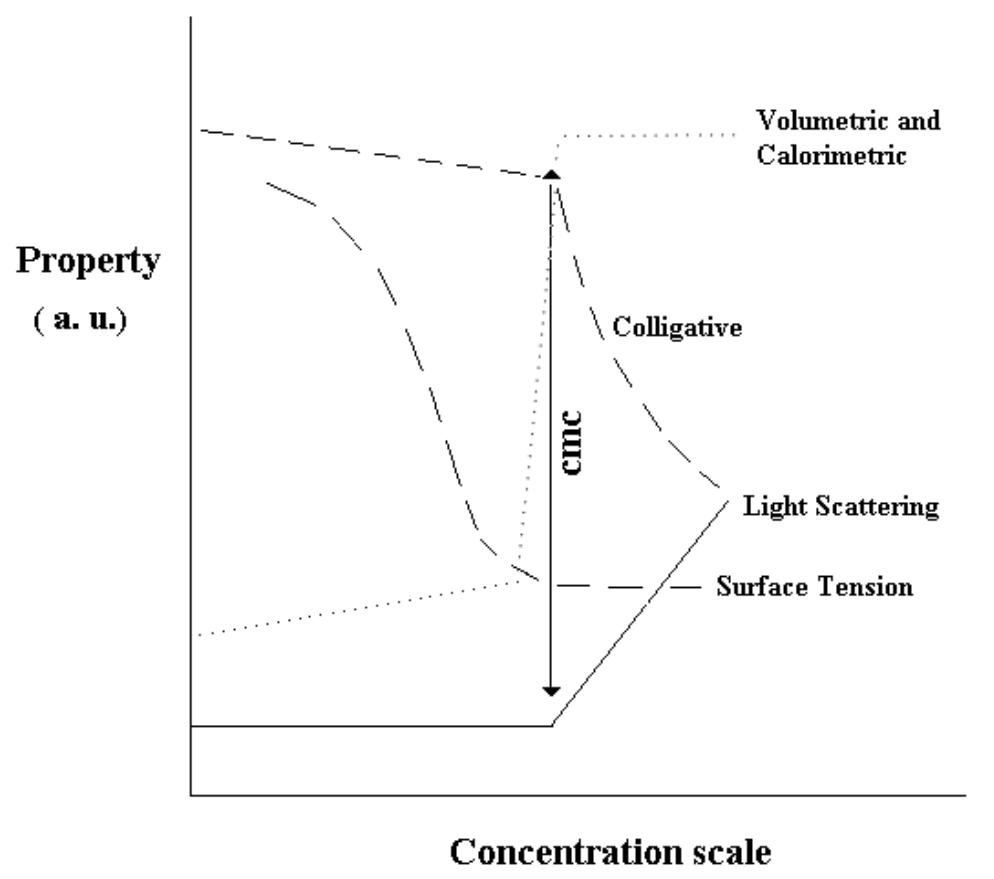

Micelle formation is strongly cooperative. When the number of associating molecules is large, the formation of micelle fulfils a (pseudo) phase-separation model [38] and the corresponding Gibbs energy of formation, $\Delta G^{\circ}$ mic , can be expressed as

$$
\Delta G_{\text {mic }}^{\circ}=R T(1+\beta) \ln \mathrm{cmc}
$$

where $\beta$, the counter-ion binding degree, is introduced in case of ionic species. $\beta$ is related to ion dissociation from the micelle surface, $\alpha$, according to the equality $\beta=1-\alpha$. Micelles are charged entities, with counter-ions condensed on their outer surface, and show ionic mobility and selfdiffusion. These properties are, obviously, significantly lower than those observed in simple ions or small molecules [39].

$B S$ fulfil some conditions inherent to micelle formation, but their association modes are not cooperative. The number of associating molecules in the aggregates is low and concentration (or ionic strength) dependent [40]. DLS shows that the hydrodynamic diameter of BS aggregates, in the absence of salts, can be as low as $1 \mathrm{~nm}$. Such value is close to the lower limit of the colloid range.

The association features of bile salts have been evaluated and it was assumed that $B S$ aggregation is "non critical" [41]. The latter term defines non-cooperative and continuous (i.e. concentration dependent) association features. This is the reason why some authors do not include $B S$ in 
compilations of $\mathrm{cmc}$ values [37,42]. BS aggregates may have more critical concentrations, well separated each from the other [43]. The above questions are not merely of academic interest and may help understanding why sterol solubility in BS has a complex dependence on concentration. Nowadays it is accepted to define aggregates formed by $B S$ association as micelles, although they do not fulfil all requirements pertinent to such entities. In analogy with what observed in short alkyl chain surfactants, the $c m c$ of $B S$ is considered a concentration range rather than a critical value [44].

The first attempt to define the structure of BS micelles is due to Small [45], who defined the hierarchy of forces driving their association and assumed that primary, small aggregates are held together by hydrophobic interactions between the steroidal units. In his model, secondary micelles are formed by hydrogen-bond interactions between primary aggregates. In words, formation of large $B S$ micelles finds analogy with a necklace made of pearls.

Small's hypothesis was questioned. Some authors inverted the order of driving forces responsible for aggregation and supposed that association was primarily driven by hydrogen bonds [46]. This was strongly criticised and soon rejected [47-49]. Other authors suggested that the structure of bile salt micelles is similar to helical steroidal complexes [50-52], in analogy with the behaviour observed in gels made of acidified and partly neutralised un-conjugated BS [53]. In fact, an increase in BS content or in ionic strength gives rise to long rod-like micelles. Refinements of the latter hypothesis are still under investigation [54-58] and efforts are made to relate the structure of BS micelles with those of the liquid crystalline, fibres and solids they may form [59].

Micelle growth in $B S$ is documented by a lot of experimental evidence, based on viscosity [60-64], DLS and QELS [65-69], NMR self-diffusion [70,71] and so forth [72-74]. Such data point out to the existence of an almost continuous association process, driven by surfactant uptake onto micelles and/or by the screening of the electrostatic repulsions occurring between them. An indication of micelle growth is shown in Figure 4, where self-diffusion values relative to micelles made of sodium tauro-deoxycholate, NaTDC, and of the corresponding taurocholate, NaTC, are reported.

Figure 4. Surfactant self-diffusion, $D$, in $10^{-10} \mathrm{~m}^{2} \mathrm{~s}^{-1}$, vs. surfactant wt\%, for NaTC, circles, and NaTDC, squares, at $25.0^{\circ} \mathrm{C}$. Data are in semi-logarithmic scale. They refer to the region of existence of the solution phase. Note the significant differences between NaTC and NaTDC.

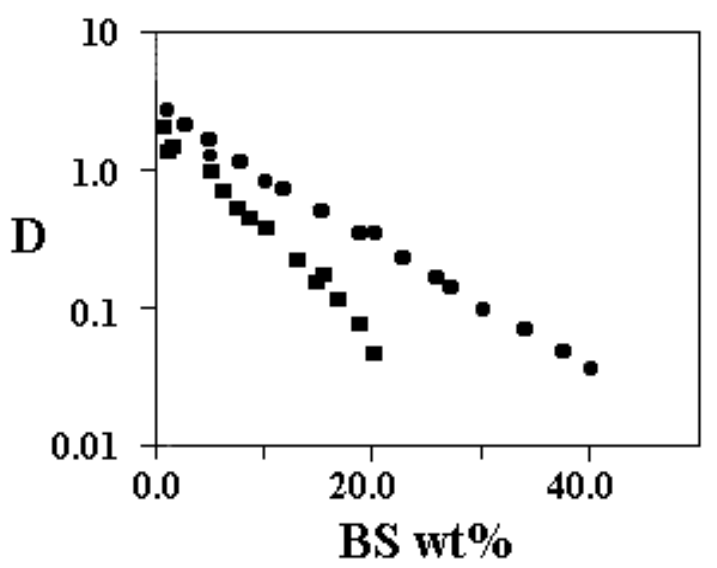


The self-diffusion of large aggregates decreases significantly compared to dilute micellar solutions. This is a strong indication of significant micelle growth in one (or two) direction. The selfdiffusion values give the average hydrodynamic micelle radius, $R_{H}$, calculated according to the wellknown Stokes-Einstein equation.

\section{Structural organisation}

$B S$ are by far more bulky and rigid compared to fatty acids, glycerides and lipids. This peculiarity has consequences in supra-molecular organisation and accounts for the formation of mixed aggregates with other amphiphilic species. To ascertain which contributions dominate and which structures may be formed requires the support from experimental and theoretical methods. Thermodynamic, structural, transport and spectroscopic properties can solve the problem, in conjunction to molecular modelling and energy calculations. Comparison with simple surfactants is also fruitful.

In normal surfactants, the hydrophobic interactions between alkyl chains give rise to an energy contribution of $\approx 650 \mathrm{cal} \mathrm{mol}^{-1}$ per mole of $\mathrm{CH}_{2}$ groups. This effect is related to the transfer of polymethylene chains from water to micelles, whose interior is non-polar. In BS the transfer contribution is hardly rationalised, because next neighbours interactions between non-polar parts of the steroidal units are complicated by their rigidity. In addition, stabilising effects due to hydrogen bonds occur. The latter depend on the distance and the reciprocal orientation between $\mathrm{OH}$ groups facing outside the $\mathrm{BS}$. This is the reason why quantification in energy terms of $B S$ micelle structure is cumbersome. Such behaviour is reflected, for instance, in solution calorimetry. The enthalpy change associated to micelle formation in short chain alkyl glycosides is about $6-7 \mathrm{~kJ} \mathrm{~mol}^{-1}$ [75], but it is as low as $1.0 \mathrm{~kJ} \mathrm{~mol}^{-1}$ for NaTDC [76,77].

The alkyl chains of fatty acids, lipids and glycerides have many degrees of freedom, which ensure them very significant tail-to-tail interactions with close neighbour molecules. Accordingly, their packing ensures the formation of micelles, vesicles and liquid crystalline phases. The alkyl chains of fatty acids and glycerides are mobile and exist in a fluid state. No such possibilities are allowed to BS. Their reciprocal arrangement must maximise hydrophobic interactions between the apolar residues of different molecules, minimise electrostatic repulsions and allow stabilising effects ascribed to hydrogen-bond interactions. This behaviour is qualitatively reminiscent to base stacking interactions between flat molecules, such as dyes [78]. The constraints given above imply that micelle structures of $B S$ are unconventional. On these grounds, it was stated that BS could not form liquid crystalline phases [79]. This hypothesis was accepted and contradicted only in recent years [80-83].

\section{Binary Phase Diagrams}

In the following, binary phase diagrams for the most common bile salts are reported. Compared to other surfactant systems, the phase diagrams of water- $B S$ mixtures have a puzzling behaviour. In particular, the coexistence of solid and liquid crystalline forms, at $T$ above the Krafft point, is not observed in common surfactants [84].

The kinetics of phase transitions in aqueous BS is astonishingly slow. In concentrated solutions days are required to attain thermodynamic equilibrium conditions. The reasons for that behaviour are tentatively ascribed to the difficulty for $B S$ molecules to find an optimal arrangement. The whole 
kinetic sequence, with alternate phase separation and mixing processes, is largely different from that observed in the formation of liquid crystalline phases composed by surfactants or lipids. In Figure 5 is schematically indicated what happens when concentrated solutions are dealt with.

Figure 5. Phase evolution with time, in hours, in a solution containing $41.5 \mathrm{wt} \%$ sodium taurodeoxycholate, NaTDC, viewed between crossed polarisers. The solution was formerly heated and equilibrated at $25.0^{\circ} \mathrm{C}$. Note the presence of an upper anisotropic layer, changing its thickness and consistency with time (lanes 2-4), the formation of small crystals in the bottom (lanes 2 and 3), creaming (lane 4), and formation of a birefringent, liquid crystal (lane 5).

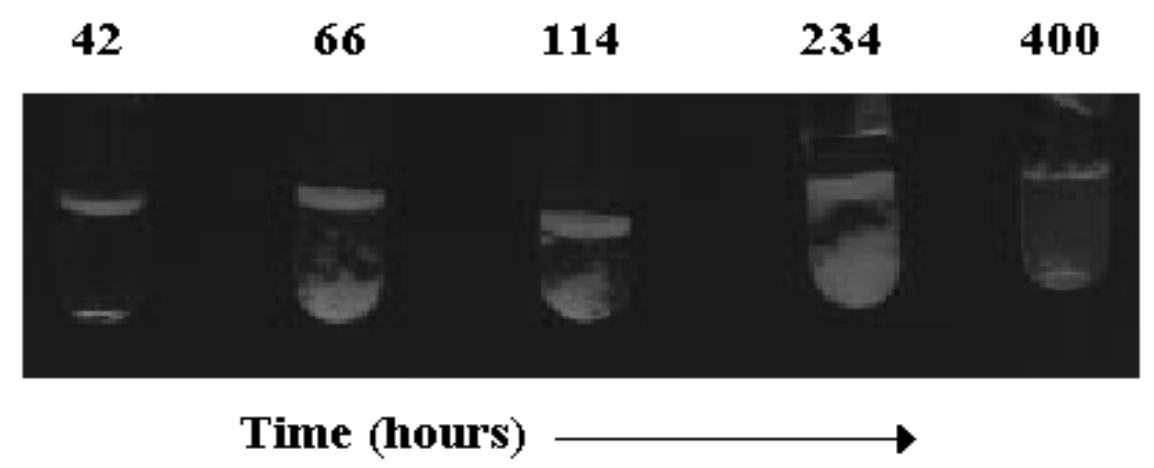

Transformations occurring in such mixtures follow an unusual kinetic scheme, which obeys the following temporal sequence. In many hours, concentrated solutions split in two phases, a transparent liquid and a weakly birefringent upper fluid. Several hours after, spherulitic crystals nucleate in the bottom of the transparent liquid, move toward the upper birefringent phase (in a creaming process) and merge in it. Days later the whole mixture becomes macroscopically homogeneous and optically anisotropic. In polarised light, the birefringence of these samples is similar to that observed in diluted lyotropic liquid crystals, Figure 6. The optical anisotropic textures observed by optical polarising microscopy are reminiscent of those occurring in normal surfactants and lipids [85,86].

Figure 6. Optical anisotropic textures observed by polarising microscopy, at $20{ }^{\circ} \mathrm{C}$, in water-sodium deoxycholate $(\mathrm{NaDC})$ mixtures. From the left, fibres (26.6 wt \%), random and ordered anisotropic domains (47.1 wt \%), at equilibrium, or by shearing the sample between glass slides. The last image suggests rod-like, or fibre-like, arrangement. Magnification is $200 \mathrm{x}$.
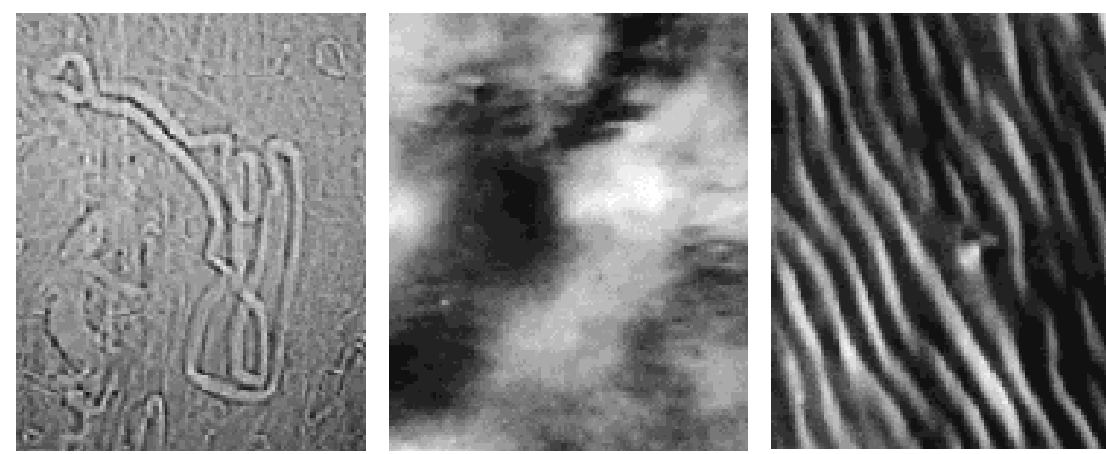
The phase behaviour of some binary aqueous BS mixtures of sodium deoxycholate, NaDC, NaGDC (sodium glycodeoxycholate) and NaTDC (taurodeoxycholate)-water systems is shown in Figures 7a-c. Deoxycholate, its glycol- and tauro- derivatives differ from each other only in the polar head groups. Despite such small variations in molecular structure, the widths and regions of existence of the phases are significantly different each from the other. The thermal stability of the liquid crystalline meso-phase is moderate and its upper limit never exceeds $35^{\circ} \mathrm{C}$. A similar behaviour holds for chenodeoxy and taurocholate salts. Very presumably, the moderate thermal stability for the above systems implies a significant contribution due to hydrogen-bond interactions. This hypothesis is far from being fully convincing, since other lyotropic phases show the same thermal behaviour [87].

Figures 7a-c. Partial phase diagrams of the water-NaDC, upper left, of the water$N a T D C$, upper right, and of the water-NaGDC binary systems. Single phase and multiphase areas are indicated. More concentrated mixtures consist in hydrated crystals and are not reported.
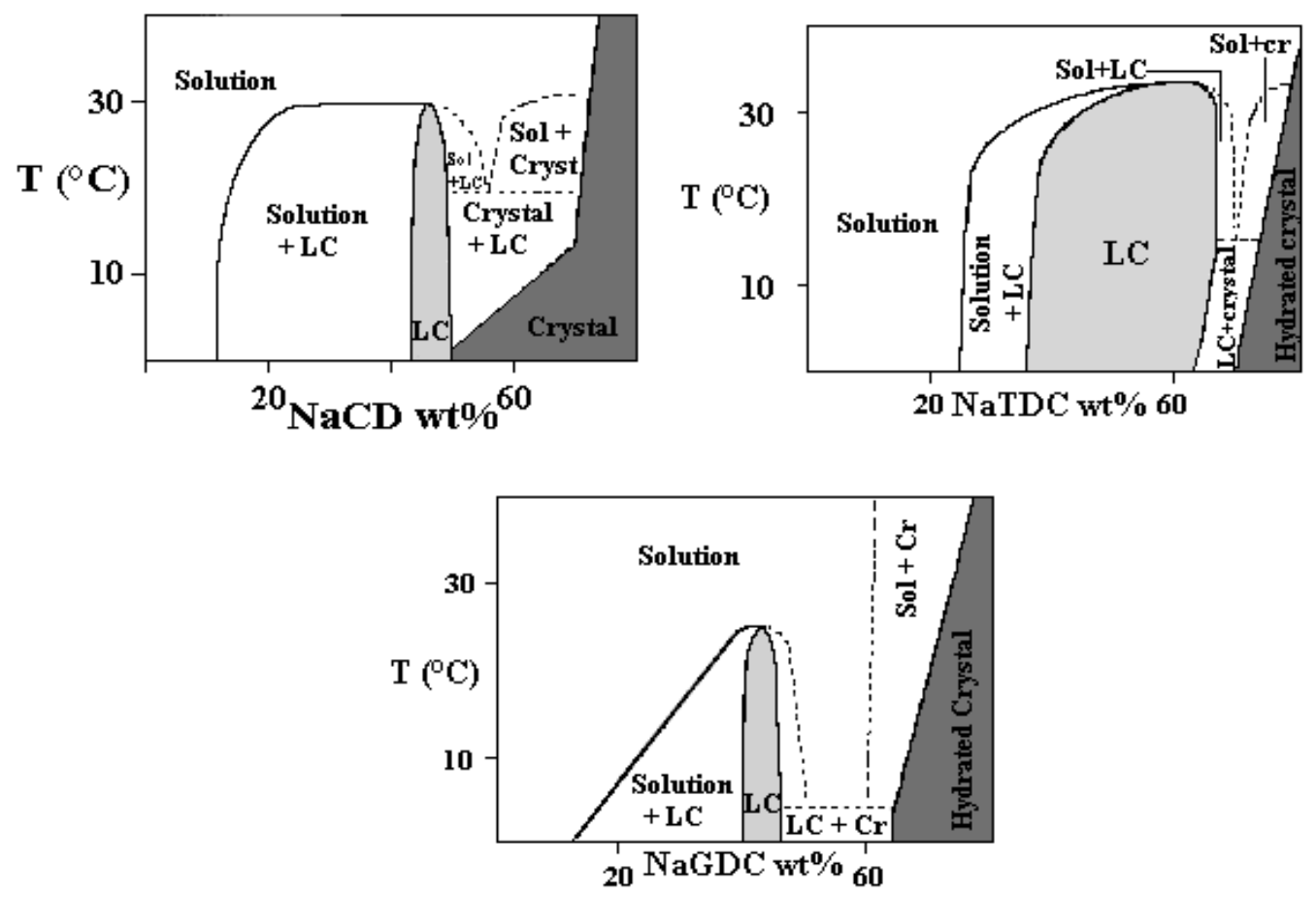

A strong similarity exists between the structure of $B S$ fibres and of liquid crystalline phases [59]. The stability of $B S$ fibres is controlled by hydrogen-bond interactions, forming an extended network. By analogy, it is tentatively assumed that the structure of the liquid crystalline phases is stabilised by the same kind of intermolecular forces. Experimental support to the aforementioned hypotheses is required. Perhaps, the situation arising from an analysis of such data is problematic, since SAXS (small angle X-ray scattering) and ${ }^{2} H$-NMR studies give conflicting evidence. 
Figure 8. SAXS spectrum of a sample (48.4 wt\%) in the water-NaTDC, at $25.0{ }^{\circ} \mathrm{C}$. The presence of peaks, in the order 1:1.73:1.89, is representative of a hexagonal structure.

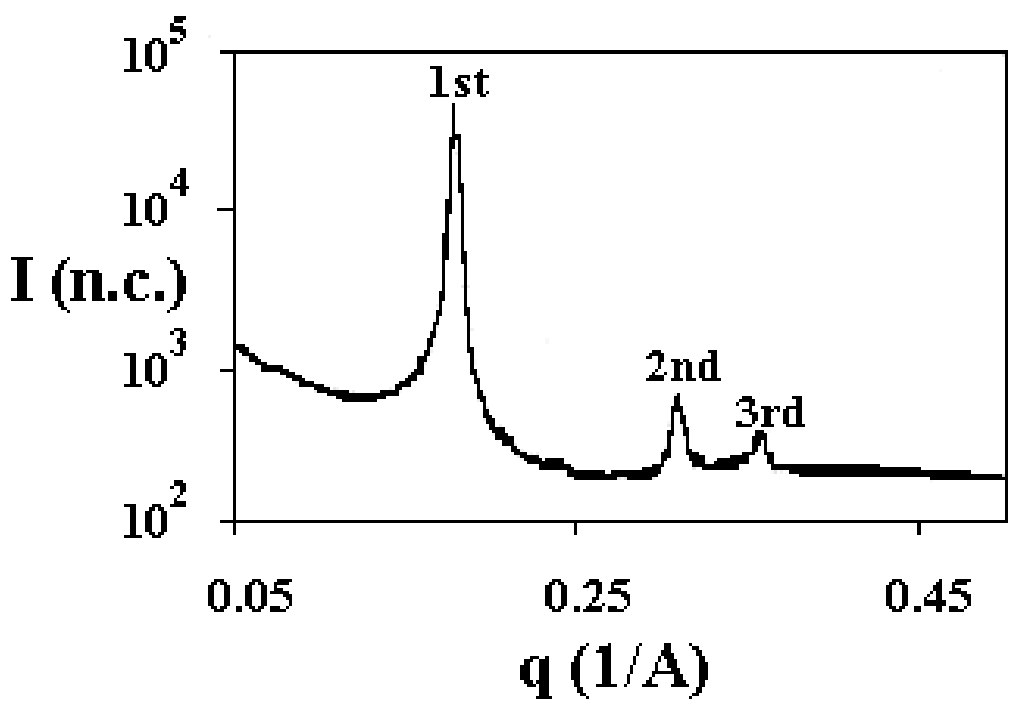

SAXS data indicate that $B S$ organisation in liquid crystalline form is reminiscent of a hexagonal structure (Figure 8). In normal surfactants, or lipids, SAXS experiments indicate that lamellar, hexagonal, or cubic, liquid crystalline phases possess long-range structural order, with well-defined Bragg reflections, resulting from the constructive interference of the reflected X-rays [88].

Figure 9. Proposed cylindrical arrangement of $B S$ into reverse hexagonal liquid crystalline phases. Each unit represents a BS, with polar regions, in black, pointing toward the inner part of the cylinder. The structure has a six-fold symmetry axis. The above cylinders are arranged into a hexagonal pattern.
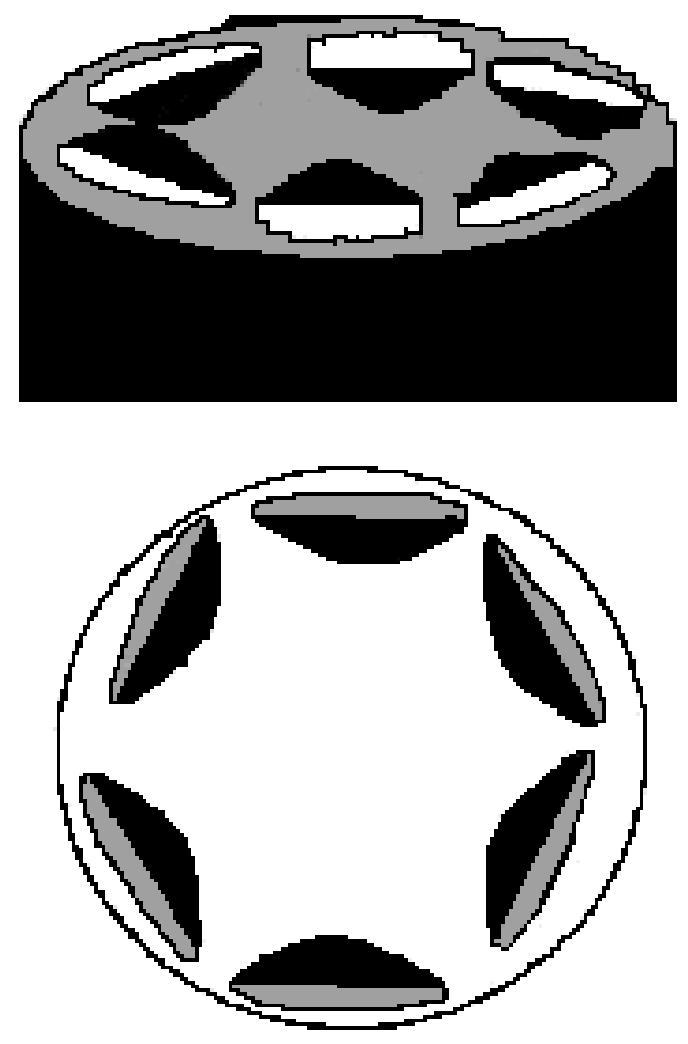
In $B S$, the (pseudo) hexagonal phase is built up of indefinitely long cylindrical aggregates packed into a two-dimensional hexagonal array. The Miller indices take the values $1, \sqrt{3}, \sqrt{ } 4, \sqrt{ } 7$, and $\sqrt{ } 9$, corresponding to the first five (hk) reflections, (10), (11), (20), (21), and (30). The reverse hexagonal phase, made of polar cylinders in a non-polar continuum fulfils similar rules [89]. In all binary systems composed of BS, SAXS data clearly point to a hexagonal-type liquid crystal. Such data are consistent with the formerly reported optical textures. These phases are built up of not conventional aggregates. They have a close structural connection with long rod-like aggregates (or fibres) drawn from concentrated isotropic solutions, for which Rich and Blow proposed a helical structure [53]. Bearing in mind such results and the location of the phases in the phase diagram, we assumed that the liquid crystalline phases made up of $B S$ have a reverse hexagonal structure, with the polar groups facing inward the cylinders, as indicated in Figure 9.

$N M R$ of quadrupolar ${ }^{2} \mathrm{H}$ nuclei of heavy water in $B S$ mixtures are largely different from those expected in canonical lyotropic mesophases, [90], Figure 10. A general observation is that ${ }^{2} \mathrm{H}$ splitting is hardly detected for the liquid crystalline phase in several binary systems made of $B S$ and may occur with superimposed isotropic signals. In addition, the water deuteron peak consists of a very broad signal. As the concentration increases toward the two-phase region, singlet and splitting are observed, with coexistence of isotropic and anisotropic phases. The deuterium NMR quadrupolar splitting are much smaller than those observed for typical liquid-crystalline phases [91-93]. This effect might result from very small values of the order parameter for water binding, indicating a small degree of anisotropy.

Figure 10. ${ }^{2} H$-NMR spectra of different liquid crystalline samples, made up of heavy water and different $B S$, at room temperature. The quadrupole splitting, i.e. the distance between the two upper peaks, can be detected. In the water-NaTDC system the quadrupolar splitting overlaps with an isotropic signal, due to the coexistence of liquid crystalline and solution phases. The $500 \mathrm{~Hz}$ wide bar indicates the amplitude of quadrupolar splitting. Spectra relative to $N a D C$ suggest that many chemically different binding sites for heavy water exist. The overall spectrum is originated by the overlapping of many contributions.

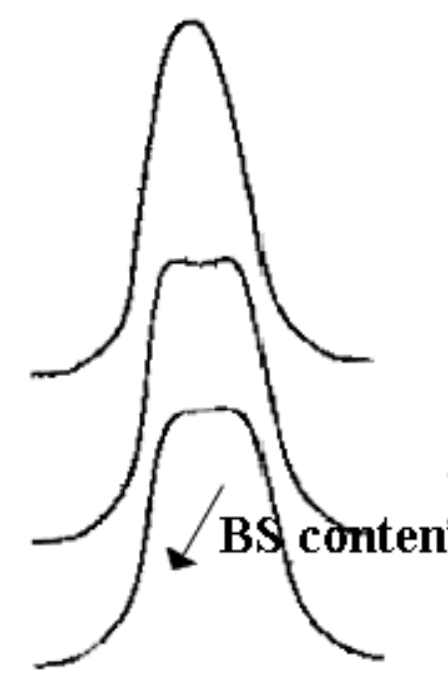

$\mathrm{NaDC}$

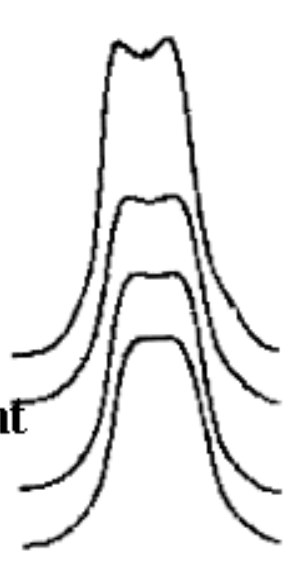

NaGDC

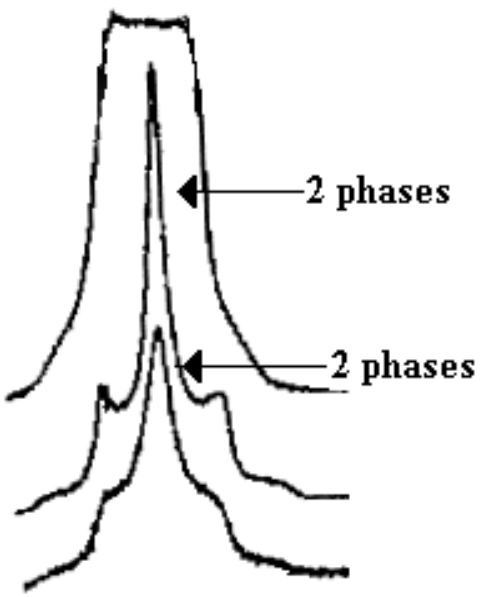

NaTDC 
The non-appearance of ${ }^{2} \mathrm{H}$ splittings for anisotropic phases has been previously reported [94]. The broad signals observed are an indication that fast exchange conditions (between "free" and "bound" water) are not fulfilled, because the micro-crystallites forming the lyotropic domains are not large enough (not even after weeks of undisturbed aging). Attempts were made to determine what reciprocal organisation of BS fulfils the formation of fibres and liquid crystalline structures.

It is supposed that $B S$ organise into rod-like structures, with distinct polarity between the inner and outer parts, Figure 10. If the above hypotheses are fulfilled, the phase behaviour is very different compared to surfactants and lipids, where small modifications in chemical structure of the solute do not imply significant changes in the phase sequence [33,95].

\section{Ternary Systems}

Following the statement that “conjugated and free BS form micelles, but not liquid crystals” [79], many authors investigated their role in the polymorphic behaviour of water-surfactant (or lipid) systems. Classical papers on BS plus lecithin and/or sterols demonstrated the existence of solubility threshold, when the solution or liquid crystalline phases coexist with cholesterol in solid form [96103]. These phase diagrams were used to define the maximum tolerance limits of cholesterol in a given medium and served as indicators of the upper concentration for sterols uptake in dietary prescriptions. Such studies suffer from some drawbacks, ascribed to the fact that lipids are not chemically pure substances, but mixtures of homologues.

Studies on ternary, or higher order systems must conform to the phase rule, to give physically consistent results. Thus, mixtures of uncertain composition, or possible chemical reaction between the components (due to the formation of mixed salts) should be avoided. In addition, the regions of existence of liquid crystalline forms for lipids and their mixtures depend on temperature [104], and gels may be formed below a given $T$ value.

Defining the region of existence for the different lyotropic phases in multi-component lipid mixtures is a very complicated task. It became urgent, for the above reason, to shed light on systems formed by BS and pure surfactants, or long-chain alkanols. Along this line, Fontell and his colleagues performed extensive work. Fontell showed that sodium deoxycholate forms a continuous solution region in the water-decanol-NaDC system and proposed that no transition occurred on going from polar to non-polar media [105]. This behaviour is in patent contradiction with what observed in mixtures of water-long chain alkanols and fatty acid soaps, where water-continuous and oil-continuous phases are separated [106].

Later studies focused on the behaviour of $B S$ in mixture with single-chain surfactants, such as $S D S$ (sodium dodecylsulfate), CTAB (cetyltrimethylammonium bromide) or Triton TX 100 (an alkylphenol with poly-ethylene oxide as polar group) [107,108]. It was observed that cubic liquid crystalline phases, not occurring in the parent binary systems, were formed in the central region of the phase diagrams.

More recently, the ternary system composed by water, monolein (a monoglyceride) and NaTDC was reported [109]. The system containing sodium taurodeoxycholate and a double chain surfactant, $D D A B$ (didodecyldimethylammonium bromide) was also presented [110]. The latter system is especially interesting, since $D D A B$ is used in mixture with lipids and imparts a positive charge to the resulting vesicles [111]. In that system a wide solution region extends from the BS-rich side up to the 
$D D A B$-rich one. The viscosity therein obeys a very puzzling dependence on composition [112]. In addition to such an unconventional behaviour, it was also observed the formation of different liquid crystalline phases, vesicles and the coexistence of two dispersions.

More recently, studies were performed on ternary systems containing water, NaTDC and bovine serum albumin, BSA [113,114]. The reasons for that investigation arise from the presence of such protein in a wide number of biochemically relevant pools. BSA and the human analogue, HSA, are capable of binding significant amounts of lipids, fatty acids and BS. They are carriers of the above substances in a wide range of physiological conditions. In dilute regimes BS bind to the protein, as a result have electrostatic and hydrogen bond interactions. This is put in evidence by ionic conductivity, suggesting that a significant number of $B S$ molecules may bind onto the protein (Figure 11). The number of surfactant molecules moving as a whole kinetic entity with BSA is close to that required neutralising the positively charged sites of albumin, $\approx 18-20$ in spontaneous $\mathrm{pH}$ conditions (about 6.5). Above that limit, the ionic conductivity increases, until free BS micelles begin to form, and decreases there from. This behaviour is reminiscent of that observed in aqueous mixtures composed by fatty acid salts and $B S A$, where small amounts of the salt are strongly bound in the protein hydrophobic tasks [115].

Figure 11. Equivalent conductance plot, $\Lambda$ (in $\mathrm{S} \mathrm{cm}^{2} \mathrm{eq}^{-1}$ ) vs. the $B S / B S A$ mole ratio, at $25.0^{\circ} \mathrm{C}$. The minimum in the curve indicates the protein titration threshold by NaTDC, and corresponds to a number of BS molecules per protein between 18 and 20. Its value increases when $\mathrm{pH}$ is lower than 5.0.

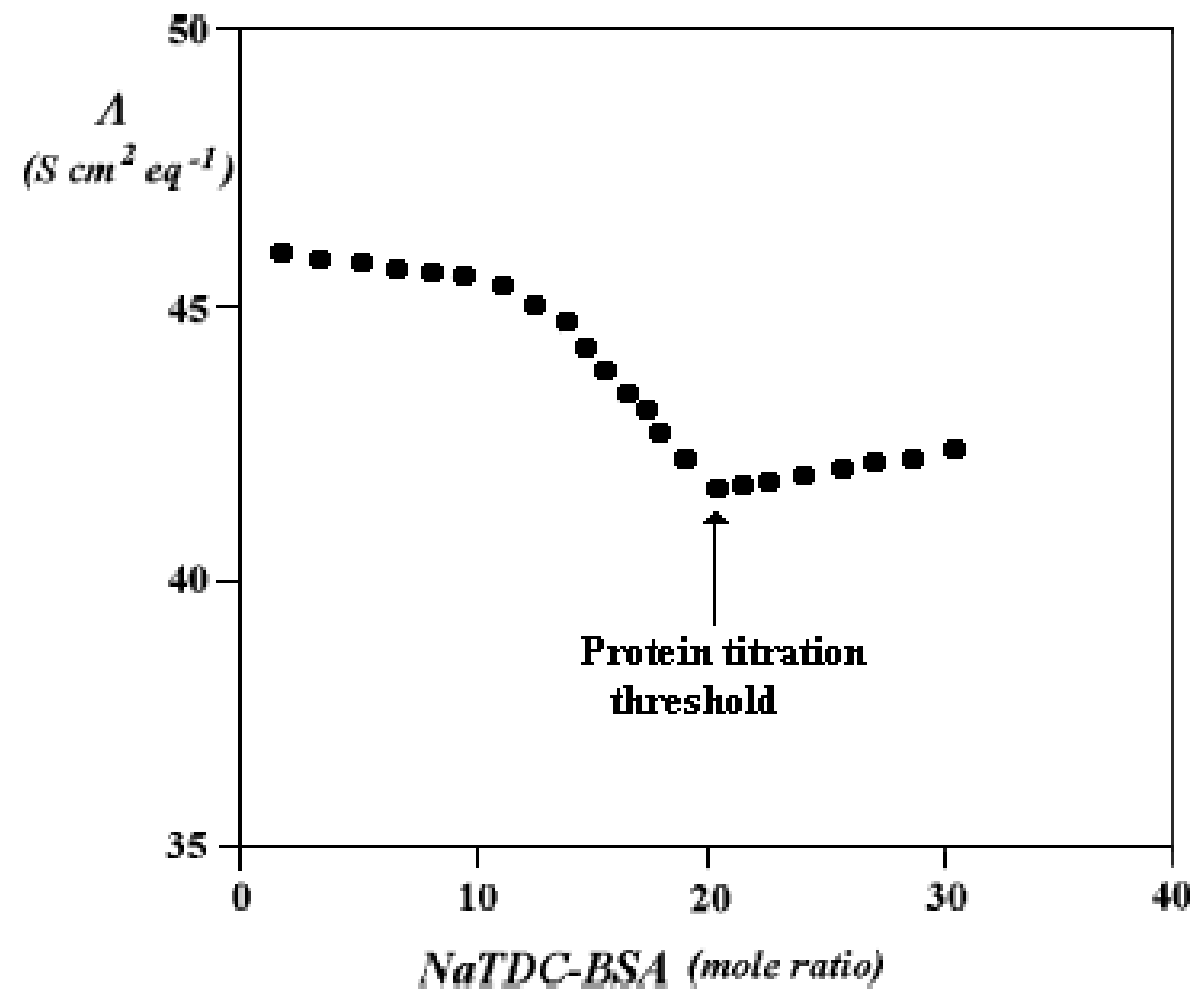

Even more interesting is the phase behaviour in the corresponding ternary system. The intensive variables ( $\mathrm{pH}$ and temperature) and the concentration of protein and surfactant are properly chosen to avoid phase separation or liquid crystal formation. In the water-NaTDC-BSA system a wide solution region is observed on the $B S$-rich and the protein-rich sides, respectively [113] (Figure 12). In the 
central part of the phase diagram, at water content close to $90 \mathrm{wt} \%$, a gel phase emerges from the solution. The gel is highly viscous and does not flow. Rheology experiments indicate that it is elastic at low temperatures and mainly viscous above a thermal gelation threshold, $T_{G}$. The gel is a separate phase, since two-phase regions can be observed around it. It is, very presumably, water-continuous, since $\mathrm{H}_{2} \mathrm{O}$ self-diffusion is very close to that pertinent to neat water. In words, hindrance to water motion is moderate.

Figure 12. Partial phase diagram of the ternary system water-NaTDC-BSA, at $25.0{ }^{\circ} \mathrm{C}$ and $\mathrm{pH}$ 6.4. The gel, in dark grey, is essentially elastic at temperatures below $40.0^{\circ} \mathrm{C}$ and becomes viscous above that limit. The two-phase region gel + solution is in light grey colour. The dotted lines in the low left side of the figure indicate precipitation when the $\mathrm{pH}$ is 5.0, light grey, or 3.0, black colour, respectively.

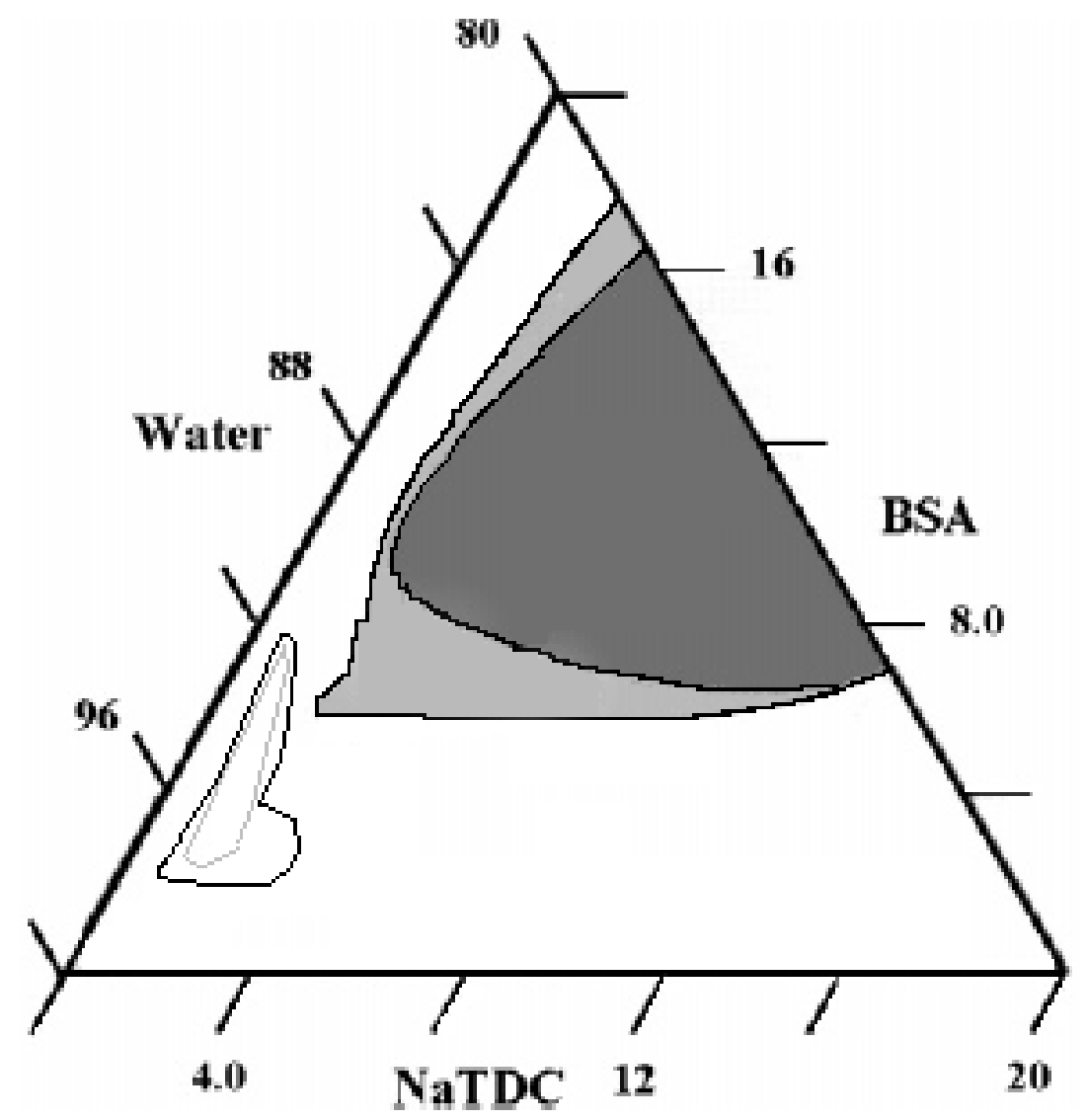

$\mathrm{pH}$ has a very funny influence on the phase behaviour, with occurrence of a tiny precipitate area at $\mathrm{pH}=5.0$. Such region widens when the $\mathrm{pH}$ decreases to 3.0. The above $\mathrm{pH}$ values refer to conditions in which the protein is close to its iso-electric point (when BSA has an ellipsoidal shape, in the former case) or when a transition to an elongated fibrous structure occurs [116,117]. The number of binding sites on the protein may change significantly on going from the spontaneous $\mathrm{pH}$ conditions to $\mathrm{pH} 5$ or $\mathrm{pH}$ 3.0.

Protein stability in the gel is higher than in water and BSA denatures at temperatures between 70.0 and $80.0{ }^{\circ} \mathrm{C}$. The denaturation temperature, $T_{D}$, regularly depends on surfactant content in the gel. (N.B. In aqueous solution and in the absence of surfactant $T_{D}$ is only $62 .{ }^{\circ} \mathrm{C}$.) Hence, gels thermally stabilise the protein conformation. The gel solubilises large amounts of drugs and may be used for the controlled release in the intestinal pool. Its thermal stability is significant and the gel is dissolved in 
presence of excess water. The dissolution kinetics is several hours long. Such behaviour is not unexpected and was observed in other water-protein-surfactant systems [118-121]. When the $\mathrm{pH}$ is lower that 5.0, the precipitate area is located between the concentration ranges pertinent to hepatic and colecystic bile, respectively [122]. This aspect deserves further investigation.

\section{Higher Order Systems}

Quaternary systems composed by water, BS, lecithin and cholesterol have been investigated in the pioneering work of Small and colleagues. For the reasons given above, it is not easy separating twophase or multi-phase regions when the lipid is not chemically pure. Egg, or soybean, lecithins are complex mixtures formed by saturated and unsaturated fatty acids, with a distribution of chain homologues from $C_{12}$ to $C_{18}$. Unsaturated chains may occur too. In such conditions, the phase diagrams refer to unspecified products, having complex phase behaviour by their own. Thus, the assignment of multiphase areas is cumbersome (unless very pure, and costly, lecithin is being used).

It was recently realised that mixtures composed by proteins, surfactants and/or lipids display a very complex phase behaviour, with occurrence of precipitates, gels, solutions, coacervates and so forth [118]. In such systems, the links between organisations of the components in a given phase, physical state and dis-metabolic diseases are significant. Studies on albumin-BS interactions are particularly relevant and may help clarifying important pharmacological aspects.

Figure 13. Simplified phase diagram of the system water, NaTDC, $C_{16}$ soybean lecithin (free from lower and unsaturated homologues) and BSA, at $25.0{ }^{\circ} \mathrm{C}$. For practical purposes, the figure was drawn as a trigonal structure, with the water axis normal to the ternary phase diagrams. Solutions (in dark grey), two-phase regions (middle grey), solutions + gel (pale), solutions plus liquid crystalline dispersions (light grey), solutions + precipitate (middle dark grey) are indicated. The gel phase extending along the BSA rich side is moderate in size. It shrinks with lecithin content and has been omitted.

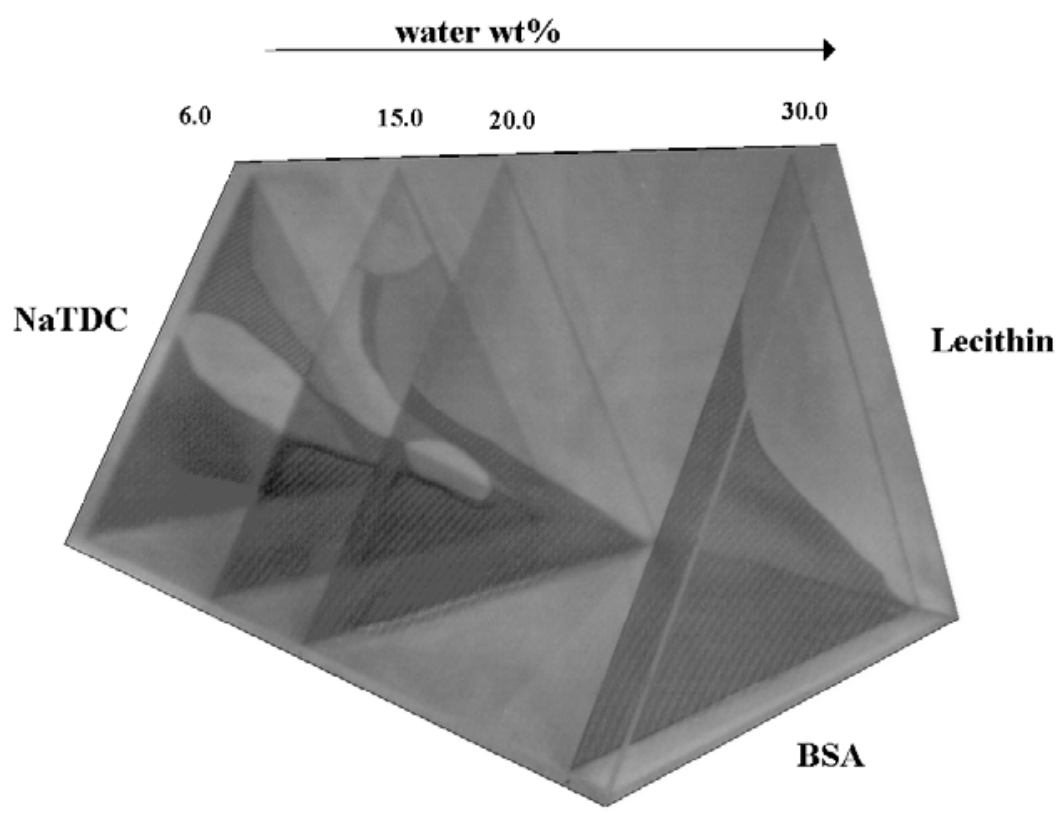


Generally, condensation-based diseases occur when pathological conditions are related to changes in solubility of specific substances and new condensed phases may be formed. Examples are the cataract, nephrolithiasis, gallstone and rheumatic pathologies, occurring when proteins denature, aggregate and precipitate in a given tissue. Denaturation is currently followed by aggregation features and occurs "in vivo", in concomitance to chronic inflammation. Albumin denaturation, for instance, was observed in rheumatic pathological conditions. These are the reasons why protein stabilisation is of outstanding relevance. For the above reasons we extended previous work on BS-BSA systems to quaternary mixtures containing lecithins. This could be an interesting model system, mimicking the conditions occurring with protein in excess. Some preliminary information on the phase behaviour is reported in Figure 13. The transition from a given phase to another is concomitant to small changes in composition [123].

The gel phase formerly observed in the water-NaTDC-BSA system dissolves tiny amounts of lecithin, up to 2.0-3.0 wt \%. The gel so formed is strongly elastic and can be cut in slides by a knife. This behaviour is reminiscent of that observed in microemulsion-based gels [124].

\section{Conclusions}

Bile salts were rationally investigated since many years as associating species and fat solubilisers. Long-term controversies were solved, thanks to an impressive amount of experimental work, based on thermodynamic and structural investigations. Such studies allowed elucidating their association modes in water and in real matrices. There is actually a general consensus on the formation of $B S$ aggregates growing in size with concentration and ionic strength.

Their solvent capacity with respects to sterols and lipids was critically evaluated and related with the supra-molecular assemblies they form. Some links between structure of BS aggregates and biological functionality in the entero-hepatic circulation are observed. In physiological conditions, the supra-molecular aggregates they form can be solutions or gels. Possible links between supra-molecular organisation modes and dis-metabolic diseases are still questions of debate.

$B S$ operate in conditions where protein denaturation occurs and it was observed that they might protect proteins from de-naturation. Clinical relevance of the above phenomena is still an open question. There are indications that $B S$ stabilise proteins. A clinical analysis of the above phenomena is still under test, although qualitative indications of a favourable effect of $B S$ on protein stability are available. These hypotheses are in qualitative good agreement with those presented here.

The effect of non anti-denaturants steroidal drugs, such as BS, on serum albumin denaturation and aggregation is currently studied by thermo-chemical, optical turbidity and HPLC methods [125,126]. It was shown that fatty acids and $B S$ are by far more active than other substances and operate at very low surfactant/protein mass ratios. This is an indication that ligand-protein interactions occur.

At high concentrations, when protein-micelle interactions become significant, the situation is undefined and controversial. In gels, very presumably, proteins are surrounded by a uniform distribution of surfactant molecules. This is reflected by the structural properties of gels in proteinsurfactant systems $[127,128]$. The interaction mechanisms are far from being completely understood and much experimental and theoretical work is required on the above purpose. The effect of concentration and the macroscopic phase properties of protein-surfactant based gels are strongly interrelated. They could be responsible for dis-metabolic diseases and for remediation procedures of 
albumin-based diseases. Such studies are at an early stage and require an extensive collaboration between scientists involved in the fundamental and applied bio-chemical aspects of protein-surfactant based gels.

\section{Acknowledgments}

Thanks are due to E. F. Marques (Porto University, PT), H. Edlund (Sundsvall University, SE), A. Khan (Lund University, SE), L. Coppola (Calabria University, IT) and L. Galantini (La Sapienza University, Rome, IT) for stimulating discussions on many aspects of this manuscript.

MIUR, the Ministry of Education, University and Research supported this work through a COFIN project on Polymer-Surfactant Systems. This research line was performed under the auspices of the European Community, by a COST D-15 Action Project on Interfacial Chemistry and Catalysis, 20062009.

\section{References}

1) Kullak-Ublick, G. A.; Stieger, B.; Hagenbuch, B; Meier, P. J. Hepatic transport of bile salts. Sem. Liver Dis. 2000, 20, 273-92.

2) Small, D.M. Role of ABC transporters in secretion of cholesterol from liver into bile. Proc. Nat. Acad. Sci. U.S.A.; 2003, 100, 4-6.

3) Small, D. M. Point mutations in the ileal bile salt transporter cause leaks in the enterohepatic circulation leading to severe chronic diarrhea and malabsorption. J. Clinical Invest. 1997, 99, 1807-1808.

4) Farthing, M. J. G.; Keusch, G. T.; Carey, M. C.; Varon, S. Effects of bile and bile salts on growth and membrane lipid uptake by Giardia lamblia. Possible implications for pathogenesis of intestinal disease. J. Clinical Invest. 1985, 76, 1727-32.

5) Sanchez-Mete L.; Attili, A. F. Cholelithiasis: genetic hypothesis. Minerva Gastroenterol. Dietol. 2000, 46, 45-55.

6) Van Erpecum, K. J.; Wang, D. Q.-H.; Lammert, F.; Paigen, B.; Groen, A. K.; Carey, M. C. Phenotypic characterization of Lith genes that determine susceptibility to cholesterol cholelithiasis in inbred mice: soluble pronucleating proteins in gallbladder and hepatic biles. $J$. Hepatol. 2001, 35, 444-451..

7) Small, D. M. Gallstones New Engl. J. Med. 1968, 279, 588-93.

8) Van Dyke, R. W.; Stephens, J. E.; Scharschmidt, B. F. Effects of ion substitution on bile aciddependent and -independent bile formation by rat liver. J. Clinical Invest. 1982, 70, 505-17.

9) Siegfried, C. M.; Doisy, E. A. Jr; Elliott, W. H. Bile acids. XLIV, quantitation of bile acids from the bile fistula rat given (4-14C) cholesterol. Biochim. Biophys. Acta 1975, 380, 66-75.

10) Blossey, E. C.; Ford, W. T.; Periyasamy, M. Carbon-13 NMR spectra of multifunctional bile acid derivatives. Magn. Res. Chem. 1991, 29, 190-193.

11) Tobin, K. A. R.; Ulven, S. M.; Schuster, G. U.; Steineger, H. H.; Andresen S. M.; Gustafsson, J.A.; Nebb, H. I. Liver $\mathrm{X}$ receptors as insulin-mediating factors in fatty acid and cholesterol biosynthesis. J. Biol. Chem. 2002, 277, 10691-10697. 
12) Craven, P. A.; Pfanstiel, J.; De Rubertis, F. R. Role of reactive oxygen in bile salt stimulation of colonic epithelial proliferation. J. Clinical Invest. 1986, 77, 850-859.

13) Gonzalez, M. C.; Sutherland, E.; Simon, F. R. Regulation of hepatic transport of bile salt. Effect of protein synthesis inhibition on excretion of bile salts and their binding to liver surface membrane fractions. J. Clinical Invest. 1979, 63, 684-694.

14) Aubert, E.; Sbarra, V.; Le Petit-Thevenin, J.; Valette, A.; Lombardo, D. Site-directed Mutagenesis of the Basic N-terminal Cluster of Pancreatic Bile Salt-dependent Lipase. Functional significance. J. Biol. Chem. 2002, 277, 34987-34996.

15) Farruggia, B.; Pico, G. Role of electrostatic forces in hydroxy and keto bile salt-albumin interactions: some experimental observations. Gen. Physiol. Biophys. 1992, 11, 219-224.

16) Donovan, J. M.; Benedek, G. B.; Carey, M. C. Self-association of human apolipoproteins A-I and A-II and interactions of apolipoprotein A-I with bile salts: quasi-elastic light scattering studies. Biochemistry 1987, 26, 8116-8125.

17) Calcamuggi, G.; Lanzio, M.; Babini, G.; Martini, S.; Anfossi, G.; Emanuelli, G. Sodium taurocholate affects prostacyclin constitutive production by cultured human vascular endothelial cells. J. Labor. Clinical Med. 1990, 115, 756-760.

18) Keynes, G. A Bibliography of the Writings of William Harvey, $2^{\text {nd }}$ ed.; Pergamon Press: Cambridge, 1953.

19) Gee, J. M.; Johnson, I. T. Interactions between hemolytic saponins, bile salts and small intestinal mucosa in the rat. J. Nutr. 1988, 118, 1391-1397.

20) Sidhu, G. S.; Oakenfull, D. G. A mechanism for the hypocholesterolemic activity of saponins. British J. Nutr. 1986, 55, 643-649.

21) Donovan, J. M.; Jackson, A. A.; Carey, M. C. Molecular species composition of inter-mixed micellar/vesicular bile salt concentrations in model bile: dependence upon hydrophilichydrophobic balance. J. Lipid Res. 1993, 34, 1131-1140.

22) Schurtenberger, P.; Svård, M.; Wehrli, E.; Lindman, B. Vesicle formation in aqueous solutions of bile salt and monoacylglycerol. Biochim. Biophys.Acta, Gen. Sub. 1986, 882, 465-468.

23) Jones, E. L.; Nassimbeni, L. R. Crystal and molecular structures of the inclusion compounds of cholic acid with methanol, ethanol and 1-propanol. Acta Crystallogr. B 1990, 46, 399-405.

24) Yoswathananont, N.; Sada, K.; Miyata, M.; Akita, S.; Nakano, K. Dependence of selective enclathration on types of cholic acid crystals. Org. Biomol. Chem. 2003, 1, 210-214.

25) Small, D. M.; Dowling, R. H.; Redinger, R. N. Enterohepatic circulation of bile salts Arch. Intern. Med. 1972, 130, 552-573.

26) Redinger, R. N.; Small, D. M. Bile composition, bile salt metabolism, and gallstones Arch. Intern. Med. 1972, 130, 618-630.

27) Hofmann, A. F.; Small, D. M. Detergent properties of bile salts: correlation with physiological function. Ann. Rev. Med. 1967, 18, 333-376.

28) Ulmius, J.; Lindblom, G.; Wennerström, H.; Johansson, L. B.-Å, Fontell, K.; Söderman, O.; Arvidson, G. Molecular organization in the liquid-crystalline phases of lecithin-sodium cholatewater systems studied by nuclear magnetic resonance. Biochemistry 1982, 21, 1553-1560.

29) Small, D. M.; Physical chemistry of cholanic acids; In The Bile Acids, Nair, P. P.; Kritchevsky, D.; Eds.; Plenum Press: New York, 1971; Vol. I, Chapt. IV, pp. 249-356. 
30) Cabral, D. J.; Hamilton, J.A.; Small, D. M. The ionization behavior of bile acids in different aqueous environments. J. Lipid Res. 1986, 27, 334-343.

31) D'Archivio, A. A.; Galantini, L.; Gavuzzo, E.; Giglio, E.; Scaramuzza, L. Possible Models for the Micellar Aggregates of Glycocholate and Taurocholate Salts from Crystal Structures, QELS, and CD Measurements. Langmuir 1996, 12, 4660-4667.

32) De Sanctis Candeloro, S.; D'Archivio, A. A.; Galantini, L.; Gavuzzo, E.; Giglio, E. On the role of hydronium ions in the protonated micellar aggregates of bile salts. Perkin 2 2000, 403-407.

33) Laughlin, R. G. The Aqueous Phase Behavior of Surfactants; Academic Press: San Diego, 1994.

34) Gu, J.; Hofmann, A. F.; Ton, N.; Huong T.; Schteingart, C. D.; Mysels, K. J. Solubility of calcium salts of unconjugated and conjugated natural bile acids. J. Lipid Res. 1992, 33, 635-646.

35) Hofmann, A. F.; Mysels, K. J. Bile acid solubility and precipitation in vitro and in vivo: the role of conjugation, pH, and Ca2+ ions. J. Lipid Res. 1992, 33, 617-626.

36) Tanford, C. The Hydrophobic Effect. Formation of Micelles, Vesicles and Membranes, $2^{\text {nd }}$ Ed.; Academic Press: New York, 1980.

37) Mukerjee, P.; Mysels, K. J. Critical Micelle Concentration of Aqueous Surfactant Systems; NSRDS, NBS: Washington, DC, 1971.

38) Shinoda, K.; Hutchinson, E. Pseudo-phase separation model for thermodynamic calculations on micellar solutions. J. Phys. Chem. 1958, 62, 577-582.

39) Stilbs, P. Fourier transform pulsed-gradient spin-echo studies of molecular diffusion. Prog. Nucl. Magn. Reson. Spectrosc. 1987, 19, 1-45.

40) Kratohvil, J. P.; Hsu, W. P.; Kwok, D. I. How large are the micelles of di-a-hydroxy bile salts at the critical micellization concentrations in aqueous electrolyte solutions? Results for sodium taurodeoxycholate and sodium deoxycholate. Langmuir 1986, 2, 256-258.

41) Roda, A.; Hofmann, A. F.; Mysels, K. J. The influence of bile salt structure on self-association in aqueous solutions. J. Biol. Chem. 1983, 258, 6362-6370.

42) van Os, N. M.; Haak, J. R.; Rupert, L. A. M. Physico-Chemical Properties of Selected Anionic, Cationic and Nonionic Surfactants; Elsevier: Amsterdam, 1993.

43) Ekwall, P. Concentration limits in association colloid solutions. J. Colloid Sci. 1954, Suppl.1, 6680 .

44) Desnoyers, J. E.; Caron, G.; De Lisi, R.; Roberts, D.; Roux, A.; Perron, G. Thermodynamic properties of alkyldimethylamine oxides in water. Application of a mass-action model for micellization. J. Phys. Chem. 1983, 87, 1397-1406.

45) Small, D. M. Size and structure of bile salt micelles. Influence of structure, concentration, counterion concentration, pH, and temperature. Adv. Chem. Ser. 1968, 84, 31-52.

46) Oakenfull, D. G.; Fisher, L. R. The role of hydrogen bonding in the formation of bile salt micelles. J. Phys. Chem. 1977, 81, 1838-1841.

47) Zana, R. The role of hydrogen bonding in the formation of bile salt micelles. Comments. J. Phys. Chem. 1978, 82, 2440-2443.

48) Oakenfull, D. G.; Fisher, L. R. The role of hydrogen bonding in the formation of bile salt micelles. Reply to comments. J. Phys. Chem. 1978, 82, 2443-2445.

49) Rajagopalan, N.; Vadnere, M.; Lindenbaum, S. Thermodynamics of aqueous bile salt solutions: heat capacity, enthalpy and entropy of dilution. J. Solution Chem. 1981, 10, 785-801. 
50) Sugihara, G.; Yamakawa, K.; Murata, Y.; Tanaka, M. Effects of pH, pNa, and temperature on micelle formation and solubilization of cholesterol in aqueous solutions of bile salts. J. Phys. Chem. 1982, 86, 2784-2788.

51) Tanaka, M.; Kodera, Y.; Sugihara, G. Colloid chemistry of free bile salts. II. Recent information on mechanism of micelle formation. Fukuoka Daigaku Rigaku Shuho 1978, 8, 29-45.

52) Briganti, G.; D'Archivio, A. A.; Galantini, L.; Giglio, E. Structural Study of the Micellar Aggregates of Sodium and Rubidium Glyco- and Taurodeoxycholate. Langmuir 1996, 12, 11801187, and references therein.

53) Rich, A.; Blow, D. M. Formation of a helical steroid complex. Nature 1958, 182, 423-426.

54) D’Archivio, A. A.; Galantini, L.; Giglio, E. X-Ray, QELS, and CD Studies of the Micellar Aggregates of Calcium Taurodeoxycholate. Langmuir 1997, 13, 4197-4203.

55) Campanelli, A. R.; Candeloro De Sanctis, S.; Giglio, E.; Petriconi, S. The structure of helices of rubidium deoxycholate-water(3/10), 3(Rb+.C24H39O4-).10H2O. Acta Crystallogr. Sect. C 1984, 40, 631-635.

56) Campanelli, A. R.; Candeloro De Sanctis, S.; Giglio, E.; Scaramuzza, L. A model for micellar aggregates of a bile salt: crystal structure of sodium taurodeoxycholate monohydrate. J. Lipid Res. 1987, 28, 483-489.

58) Campanelli, A. R.; Candeloro DeSanctis, S.; Chiessi, E.; D’Alagni, M.; Giglio, E.; Scaramuzza, L. Sodium glyco- and taurodeoxycholate: possible helical models for conjugated bile salt micelles. J. Phys. Chem. 1989, 93, 1536-1542.

57) Campanelli, A. R.; Candeloro DeSanctis, S.; Galantini, L.; Giglio, E.; Scaramuzza, L. A possible helical model for sodium glycocholate micellar aggregates. J. Inclus. Phenom. Mol. Recognit. Chem. 1991, 10, 367-377.

58) Galantini, L.; Giglio, E.; La Mesa, C.; Pavel, N. V.; Punzo, F. Sodium Taurodeoxycholate Structure from Solid to Liquid Phase. Langmuir 2002, 18, 2812-2816.

61) Fontell, K. Micellar behavior in solutions of bile acid salts. III. Viscosity and density measurements in aqueous solutions. Koll. Z. u. Z. Polym. 1971, 246, 614-625.

62) Plowiec, R.; Kielczynski, P.; D'Arrigo, G.; La Mesa, C. Dynamic shear viscosity measurements in aqueous sodium deoxycholate solutions. Adv. Mol. Relax. Interact. Proc. 1982, 24, 181-189.

63) D’Arrigo, G.; La Mesa, C. Temperature and Concentration Effects on the Viscoelasticity of Concentrated Aqueous Solutions of Bile Salts in the Ultrasonic Range. Phys. Rev. A, 1981, 24, 2187-2190.

64) Sesta, B.; La Mesa, C.; Bonincontro, A.; Cametti, C.; Di Biasio, A. Molecular aggregation of sodium deoxycholate in water and water-urea mixtures; a multistep process. Ber. Bunsen. Phys. Chem. 1981, 85, 798-803.

65) Sesta, B.; La Mesa, C.; Bonincontro, A.; Cametti, C.; Di Biasio, A. Micellization processes in concentrated sodium deoxycholate solutions - effect of different counterions. Ber. Bunsen-Ges. Phys. Chem. 1982, 86, 664-670.

66) Mazer, N. A.; Kwasnick, R. F.; Carey, M. C.; Benedek, G. B.; Quasielastic light scattering spectroscopic studies of aqueous bile salt, bile salt-lecithin and bile salt-lecithin-cholesterol solutions. In Micellization, Solubilization, Microemulsions, Mittal, K. L.; Ed.; Plenum: New York, 1977; Vol. 1, pp. 383-402. 
67) Mazer, N. A.; Carey, M. C.; Kwasnick, R. F.; Benedek, G. B. Quasielastic light scattering studies of aqueous biliary lipid systems. Size, shape, and thermodynamics of bile salt micelles. Biochemistry 1979, 18, 3064-3075.

68) Galantini, L.; Giglio, E.; Pavel, N. V.; Punzo, F. QELS and X-ray study of two dihydroxy bile salt aqueous solutions. Colloids Surf. A: Physicochem. Engineer. Asp. 2004, 248, 79-84.

69) Stark, R. E.; Gosselin, G. J.; Donovan, J. M.; Carey, M. C.; Roberts, M. F. Influence of dilution on the physical state of model bile systems: NMR and quasi-elastic light-scattering investigations. Biochemistry 1985, 24, 5599-605.

70) Hjelm, R. P.; Schteingart, C. D.; Hofmann, A. F.; Thiyagarajan, P. Structure of Conjugated Bile Salt-Fatty Acid-Monoglyceride Mixed Colloids: Studies by Small-Angle Neutron Scattering. $J$. Phys. Chem. B 2000, 104, 197-211.

71) Lindman, B. Micelles and microemulsions in ionic surfactant and bile salt systems studied by self-diffusion. Hepatology 1984, 4, 103S-109S.

72) Schurtenberger, P.; Lindman, B. Coexistence of simple and mixed bile salt-lecithin micelles: an NMR self-diffusion study. Biochemistry 1985, 24, 7161-7165.

73) D'Arrigo, G.; Sesta, B.; La Mesa, C. Evidence of viscoelastic effects in highly concentrated aqueous solutions of the bile salt sodium deoxycholate by ultrasonic measurements. J. Chem. Phys. 1980, 73, 4562-4568.

74) Berchiesi, G.; Berchiesi, M. A.; La Mesa, C.; Sesta, B. Static and dynamic studies on sodium taurodeoxycholate micellar aggregation in water in the range $25-45^{\circ} \mathrm{C}$. J. Phys. Chem. 1984, 88, 3665-3669.

75) Bonincontro, A.; D'Archivio, A. A.; Galantini, L.; Giglio, E.; Punzo, F. X-ray, Electrolytic Conductance, and Dielectric Studies of Bile Salt Micellar Aggregates. Langmuir 2000, 16, 10436-10443.

76) Capalbi, A.; Gente, G.; La Mesa, C. Solution properties of alkyl glucosides, alkyl thioglucosides and alkyl maltosides. Colloids Surf. A: Physicochem. Eng. Asp. 2004, 246, 99-108.

77) Antonelli, M. L.; Capalbi, A.; Gente, G.; Palacios, A. C.; Sallustio, S.; La Mesa, C. Thermodynamic properties of the bovine serum albumin-sodium taurodeoxycholate system. Colloids Surf. A: Physicochem. Eng. Asp. 2004, 246, 127-134.

78) Palacios, A. C.; Antonelli, M. L.; La Mesa, C. Interactions between bovine serum albumin and sodium taurodeoxycholate: thermodynamic properties. Thermochim. Acta 2004, 418, 69-77.

79) Lydon, J. Chromonic liquid crystal phases. Curr. Opin. Colloid Interface Sci. 1998, 3, 455-466.

80) Small, D. M. Liquid crystals in living and dying systems. J. Colloid Interface Sci. 1977, 58, 581602.

81) Edlund, H.; Khan, A.; La Mesa, C. Formation of a Liquid Crystalline Phase in the Water-Sodium Taurodeoxycholate System. Langmuir 1998, 14, 3691-3697.

82) Marques, E. F.; Edlund, H.; La Mesa, C.; Khan, A. Liquid Crystals and Phase Equilibria Binary Bile Salt-Water Systems. Langmuir 2000, 16, 5178-5186.

83) Amenitsch, H.; Edlund, H.; Khan, A.; Marques, E. F.; La Mesa, C. Bile salts form lyotropic liquid crystals. Colloids Surf. A: Physicochem. Eng. Asp. 2003, 213, 79-92.

84) La Mesa, C. A. Supra-molecular association in bile salts. Recent Res. Develop. Surf. Colloids 2004, 1, 97-115.

85) La Mesa, C.; Coppola, L. Krafft point solubility phenomena. Colloids Surf. 1989, 35, 325-328. 
86) Rosevear, F. B. The microscopy of the liquid crystalline neat and middle phases of soaps and synthetic detergents. J. Am. Oil Chem. Soc. 1954, 31, 628-639.

87) Rosevear, F. B. Liquid crystals: the mesomorphic phases of surfactant compositions. J. Soc. Cosmet. Chem. 1968, 19, 581-594.

88) Ekwall, P. Composition, properties, and structures of liquid crystalline phases in systems of amphiphilic compounds. In Advances in Liquid Crystals; Brown, G. H.; Ed.; Academic Press: New York, 1975; Vol. I, pp. 1-142.

89) Luzzati, V.; Mustacchi, H.; Skoulios, A.E. Husson, F. The structure of association colloids. I. The liquid-crystalline phases of the amphiphile-water system. Acta Crystallogr. 1960, 13, 660667.

90) Fontell, K. Liquid crystallinity in lipid-water systems. Mol. Cryst. Liq. Cryst. 1982, 63, 59-82.

91) Lindman, B.; Söderman, O.; Wennerström, H.; NMR studies of surfactant systems. In: Surfactant Solutions. New Methods of Investigation; Zana, R.; Ed.; Marcel Dekker: New York, 1986; Chap. VI, pp. 295-357.

92) Khan, A.; Fontell, K.; Lindblom, G.; Lindman, B. Liquid crystallinity in a calcium surfactant system. Phase equilibriums and phase structures in the system calcium octyl sulfate/decan-1ol/water. J. Phys Chem. 1982, 86, 4266-4271.

93) Marques, E.; Khan, A.; Miguel, M. G.; Lindman, B. Self-assembly in mixtures of a cationic and an anionic surfactant: the sodium dodecyl sulfate-didodecyldimethylammonium bromide-water system. J. Phys. Chem. 1993, 97, 4729-4736.

94) Tiddy, G. J. T. Surfactant-water liquid crystal phases. Phys. Rep. 1980, 57, 1-46.

95) Khan, A.; Jönsson, B.; Wennerström, H. Phase equilibria in the mixed sodium and calcium di-2ethylhexylsulfosuccinate aqueous system. An illustration of repulsive and attractive double-layer forces. J. Phys. Chem. 1985, 89, 5180-5184.

96) Larsson, K. Lipids - Molecular Organisation, Physical Functions and Technical Applications; The Oily Press: Dundee, 1994.

97) Hofmann, A. F. Micellar solubilization of fatty acids and monoglycerides by bile salt solutions. Nature 1961, 190, 1106-1107.

98) Jones, C. A.; Hofmann, A. F.; Mysels, K. J.; Roda, A. The effect of calcium and sodium ion concentration on the properties of dilute aqueous solutions of glycine conjugated bile salts: phase behavior and solubility products of the calcium salts of the common glycine conjugated bile acids. J. Colloid Interface Sci. 1986, 114, 452-470.

99) Small, D. M.; Bourges, M.; Dervichian, D. G. Ternary and quaternary aqueous systems containing bile salt, lecithin, and cholesterol. Nature 1966, 211, 816-818.

100) Small, D. M.; Bourges, M.; Dervichian, D. G. The biophysics of lipidic associations. I. The ternary systems: lecithin-bile salt-water. Biochim. Biophys. Acta, Lip. Lipid Metabol. 1966, 125, 563-580.

101) Small, D. M.; Bourges, M. Lyotropic paracrystalline phases obtained with ternary and quaternary systems of amphiphilic substances in water: Studies on aqueous systems of lecithin, bile salt, and cholesterol. Mol. Cryst. 1966, 1, 541-561.

102) Bourges, M.; Small, D. M.; Dervichian, D. G. Biophysics of lipid associations. III. Quaternary systems lecithin-bile salt-cholesterol-water. Biochim. Biophys. Acta, Lip. Lipid Metabol. 1967, 144, 189-201. 
103) Fisher, L.; Oakenfull, D. The environment of solubilized molecules in bile salt micelles. Aust. J. Chem. 1979, 32, 31-39.

104) Fontell, K. Micellar behavior in solutions of bile acid salts. Koll. Z. u. Z. Polym. 1972, 250, 333343.

105) Hay, D.W.; Cahalane, M. J.; Timofeyeva, N.; Carey, M. C. Molecular species of lecithins in human gallbladder bile. J. Lipid Res. 1993, 34, 759-768.

106) Fontell, K. Micellar behavior in solutions of bile acid salts. VI. Solutions of the three-component system bile acid salt, n-decanol, and water. Koll. Z. u. Z. Polym. 1972, 250, 825-835.

107) Jönsson, B.; Wennerström, H. Phase equilibria in a three-component water-soap-alcohol system. A thermodynamic model. J. Phys. Chem. 1987, 91, 338-352.

108) La Mesa, C.; Khan, A.; Fontell, K.; Lindman, B. Phase diagrams and NMR studies of some ternary sodium deoxycholate-surfactant-water systems. J. Colloid Interface Sci. 1985, 103, 373391.

109) Swanson-Vethamuthu, M.; Almgren, M.; Bergenståhl, B.; Mukhtar, E. The hexagonal phase and cylindrical micelles in the system alkyltrimethylammonium bromide-sodium desoxycholatewater as studied by x-ray diffraction and fluorescence quenching. J. Colloid Interface Sci. 1996, 178, 538-548.

110) Svärd, M.; Schurtenberger, P.; Fontell, K.; Jönsson, B.; Lindman, B. Micelles, vesicles, and liquid crystals in the monoolein-sodium taurocholate-water system: phase behavior, NMR, selfdiffusion, and quasi-elastic light scattering studies. J. Phys. Chem. 1988, 92, 2261-2270.

111) Marques, E. F.; Regev, O.; Edlund, H.; Khan, A. Micelles, Dispersions, and Liquid Crystals in the Catanionic Mixture Bile Salt-Double-Chained Surfactant. The Bile Salt-Rich Area. Langmuir 2000, 16, 8255-8262.

112) Szebeni, J.; Baranyi, L.; Savay, S.; Milosevits, J.; Bunger, R.; Laverman, P.; Metselaar, J.; Storm, G.; Chanan-Khan, A.; Liebes, L.; Muggia, F. M.; Cohen, R.; Barenholz, Y. Role of complement activation in hypersensitivity reactions to doxil and HYNIC PEG liposomes: experimental and clinical studies. J. Liposome Res. 2002, 12, 165-172.

113) Coppola, L.; private communication.

114) Orioni, B.; Roversi, M.; La Mesa, C.; Asaro, F.; Pellizer, D’Errico, G. Polymorphic Behavior in Protein-Surfactant Mixtures: The Water-Bovine Serum Albumin-Sodium Taurodeoxycholate System. J. Phys. Chem. B 2006, 110, 12129-12140.

115) Palacios, A. C.; Sarnthein-Graf, C.; La Mesa, C. Equilibrium between phases in water-proteinsurfactant systems. Colloids Surf. A, Physicochem. Engineer. Asp. 2003, 228, 25-35.

116) Scagnolari, F.; Roda, A.; Fini, A.; Grigolo, B. Thermodynamic features of bile salt-human serum albumin interaction. Biochim. Biophys. Acta, Protein Struct. Mol. Enzymol. 1984, 791, 274-277.

117) Nakamura, K.; Era, S.; Ozaki, Y.; Sogami, M.; Hayashi, T.; Muratami, M. Conformational changes in seventeen cystine disulfide bridges of bovine serum albumin proved by Raman spectroscopy. FEBS Lett. 1997, 417, 375-378.

118) Ferre, M. L.; Duchowicz, R.; Carrasco, B.; Garcia de la Torre, J.; Acuna, A. U. The conformation of serum albumin in solution: a combined phosphorescence depolarizationhydrodynamic modeling study. Biophys. J. 2001, 80, 2422-2430.

119) Moren, A. K.; Khan, A. Phase Equilibria of an anionic surfactant (Sodium Dodecyl Sulfate) and an Oppositely Charged Protein (Lysozyme) in Water. Langmuir 1995, 11, 3636-3643. 
120) Moren, A. K.; Khan, A. Surfactant Hydrophobic Effect on the Phase Behavior of Oppositely Charged Protein and Surfactant Mixtures: Lysozyme and Sodium Alkyl Sulfates. Langmuir 1998, 14, 6818-6826.

121) Sesta, B.; Gente, G.; Iovino, A.; Laureti, F.; Michiotti, P.; Paiusco, O.; Palacios, A. C.; Persi, L.; Princi, A.; Sallustio, S.; Sarnthein-Graf, C.; Capalbi, A.; La Mesa, C. Supramolecular Association in the System Water-Lysozyme-Lithium Perfluorononanoate. J. Phys. Chem. B 2004, 108, 3036-3043.

122) Roversi, M.; La Mesa, C. Rheological properties of protein-surfactant based gels. J. Colloid Interface Sci. 2005, 284, 470-476.

123) Aldini, R.; Montagnani, M.; Roda, A.; Hrelia, S.; Biagi, P. L.; Roda, E. Intestinal absorption of bile acids in the rabbit: different transport rates in jejunum and ileum. Gastroenterology 1996, 110, 459-468.

124) Calabresi, M.; La Mesa, C. Manuscript in preparation.

125) Fletcher, P. D. I.; Robinson, B. H. Freedman, R. B. Oldfield, C. Activity of lipase in water-in-oil microemulsions. J. Chem Soc. Faraday Trans. 1985, 81, 2667-2679.

126) Waldmann, T. A. in: Albumin: Structure, Function and Uses; Rosenoer, V. M.; Oratz, M.; Rothschild, M. A.; Eds; Pergamon: Oxford, 1977; p. 255.

127) Boye, J. J.; Inteaz, A.; Ismail, A.A. Interactions Involved in the Gelation of Bovine Serum Albumin J. Agr. Food Chem. 1996, 44, 996-1004.

128) Stenstam, A.; Montalvo, G.; Grillo, I.; Gradzielski, M. Small Angle Neutron Scattering Study of Lysozyme-Sodium Dodecyl Sulfate Aggregates. J. Phys. Chem. B 2003, 107, 12331-12338.

129) La Mesa, C. Polymer-surfactant and protein-surfactant interactions. J. Colloid Interface Sci. 2005, 286, 148-157.

(C) 2007 by MDPI (http://www.mdpi.org). Reproduction is permitted for noncommercial purposes. 